\title{
Editorial
}

\section{A responsabilidade da pós-graduação em saúde e enfermagem com o ensino fundamental e médio}

A integração dos Programas de Pós-Graduação (PPGs) no esforço de qualificação da educação básica no país é uma questão atual, colocada pela CAPES especialmente a partir da incorporação do ensino médio e fundamental ao campo de ação dessa agência, com a criação da Diretoria de Educação Básica. Conforme o Programa Nacional de Pós-Graduação (PNPG) 2005-2010 "uma pós-graduação consequente com o princípio constitucional da igualdade de oportunidades supõe o fluxo de uma educação básica forte, qualificada, equânime e democrática"1:24.

Coloca-se nos dias atuais a necessidade de uma sólida política pública para democratizar a educação infantil e o ensino médio. Essa atuação pressupõe as três etapas de acesso, permanência e qualidade do ensino, que colocam desafios ao conhecimento levado adiante pela atividade de pesquisa na pós-graduação ${ }^{1}$.

O PNPG 2011-2020 tem como um dos seus cinco eixos o apoio à educação básica e a outros níveis e modalidades de ensino, especialmente o ensino médio. No seu capitulo 8 - Educação Básica: um novo desafio para o SNPG - o documento apresenta uma série de recomendações, entre elas destaca-se aquela que prevê o estímulo à participação de cursos de pós-graduação de outras áreas do conhecimento nas questões relativas à melhoria da qualidade da educação básica ${ }^{2,3}$.

Embora as áreas de Enfermagem e Saúde não tenham atuação direta em licenciaturas, vem de longa data desenvolvendo pesquisas dirigidas a análise do processo saúde-doença de crianças e adolescentes, trabalho infantil e do adolescente, comportamentos sexuais e práticas de cuidados na adolescência, prevenção da gravidez precoce, violência na escola, uso de substâncias psicoativas e drogas, entre outras. Além dessa contribuição gerada nos PPGs, destaca-se a atuação profissional, especialmente da área de Enfermagem, voltada à promoção da saúde escolar, conforme preconizado no Programa de Saúde Escolar e no Programa de Saúde do Adolescente do Ministério da Saúde. No entanto, o largo conjunto de ações observadas em nível profissional não se articula de forma sistemática em nível da produção de conhecimentos nos PPGs.

O fato do cuidado em saúde ser um dos temas transversais no ensino médio e fundamental possibilita aos PPGs da área atuar na formação dos professores, entre outras ações. A produção de material didático para uso por professores e alunos na educação básica, a partir dos resultados das pesquisas atualmente realizadas, também pode ser objeto da produção técnica e tecnológica dos programas.

Cabe, no entanto, questionar quais as oportunidades e possibilidades de os PPGs virem a superar a contribuição pontual e local, regionalmente delimitada, para assumirem um papel mais ativo frente às metas desafiadoras postas pelo Programa Nacional de Educação e, mais especificamente, pelo Programa Nacional de Pós-Graduação, em que a educação básica assume papel de destaque, conforme apontado. Seis vertentes podem ser promissoras para a atuação dos PPGs de modo a contribuir de forma processual e coordenada para o aprimoramento do ensino médio e fundamental. Essas ações exigem, para a sua consecução, indução das diferentes Coordenações de Área da Saúde, inclusive a Enfermagem, e da CAPES:

- Constituição de redes de cursos que possam contribuir para a formação dos docentes, com recorte interdisciplinar do cuidado em saúde, envolvendo distintos PPGs desse campo de conhecimentos.

- Desenvolvimento de pesquisas participantes envolvendo professores e alunos do ensino médio e fundamental, de forma a socializar o conhecimento científico já construído na Enfermagem e na Saúde para a produção de conhecimento novo sobre a saúde escolar.

- Priorização da oferta de iniciação científica para alunos do ensino médio, através do Programa Institucional de Bolsas de Iniciação Científica para o Ensino Médio - PIBIC-EM do CNPQ, possibilitando maior aproximação de crianças e adolescentes aos laboratórios de pesquisa, alunos de pós-graduação e pesquisadores.

- Atuação, através do desenvolvimento de estágios discentes de pós-graduação, nas iniciativas do Programa Interministerial Saúde na Escola, desenvolvido em parceria pelo Ministério da Educação e o Ministério da Saúde. 
- Criação de periódicos especializados ou edição de números especiais de periódicos da área da saúde destinados à socialização do conhecimento produzido para os ensinos médio e fundamental.

- A nova política em relação à disseminação de creches pelo país abre um espaço particularmente importante para a atuação de profissionais diversos que demandam profundo conhecimento da saúde, dos cuidados com a infância e dos processos de desenvolvimento infantil que podem ser apoiados, em grande medida, pelos PPGs de Enfermagem e Saúde.

As linhas de pesquisa atualmente desenvolvidas nos PPGs de Saúde apresentam importante potencial de aplicação ao contexto do ensino médio e fundamental, especialmente aquelas voltadas à promoção da saúde, à saúde da criança e do adolescente, a gestão dos processos de ensino em saúde, ao desenvolvimento metodológico da pesquisa em saúde, além daquelas já existentes que se ocupam da saúde escolar como objeto de interesse e preocupação.

Para as áreas da Saúde e da Enfermagem essa é uma discussão ainda incipiente e pouco aprofundada no campo da pós-graduação, especialmente considerando o pequeno número de linhas e de projetos de pesquisa com foco nessa problemática. Esse quadro aponta para a necessidade de maior problematização da questão no âmbito coletivo, de forma a produzir proposições que reflitam a mobilização da área para o enfrentamento prioritário do problema.

Denize Cristina de Oliveira

Ediitora Associada

Professora Titular do PPGENF/UERJ e do PPGPS/UERJ

\section{Referências:}

1. Ministério da Educação (Br). Coordenação de Aperfeiçoamento de Pessoal de Nível Superior. Plano Nacional de Pós-Graduação - PNPG 2005-2010 / Coordenação de Pessoal de Nível Superior. Brasília (DF): CAPES; 2004.

2. Ministério da Educação (Br). Coordenação de Aperfeiçoamento de Pessoal de Nível Superior. Plano Nacional de Pós-Graduação - PNPG 2011-2020 / Coordenação de Pessoal de Nível Superior. Brasília (DF): CAPES; 2010.

3. Ministério da Educação (Br). Coordenação de Aperfeiçoamento de Pessoal de Nível Superior. Comissão Especial de Acompanhamento do PNPG 2011-2020 e Elaboração da Agenda Nacional de Pesquisa. Relatório Final. Brasília (DF): CAPES; 2013. 